\title{
Peeling of small diameter rubber log using spindleless lathe technology: evaluation of veneer properties from outer to inner radial section of log at different veneer thicknesses
}

\begin{abstract}
Rubber forest plantation (RFP) in Malaysia was currently governed by small holders who provided lower diameter logs as they managed plantation using higher planting density, higher frequency tapping practice and young-tapping systems to enhance latex harvesting yield and fulfil demand for rubber timber. Nevertheless, these new planting systems will affect the growth of rubber tree and result in the production of smaller diameter $(<20 \mathrm{~cm})$ rubber logs compared to conventional planting systems. Hence, this raises the question of the small diameter log with respect to its impact on veneer quality. The aim of this study is to determine the properties of rubberwood veneers manufactured from outer to inner radial section of $\log$ at different veneer thicknesses. The rubber logs with diameter less than $20 \mathrm{~cm}$ were peeled up to $3 \mathrm{~cm}$ of peeler core to produce 1,2 and $3 \mathrm{~mm}$ veneer thickness using spindleless lathe. Veneer properties such as thickness variation, lathe checks, surface roughness and contact angle were evaluated from outer to the inner radial section of log at three different veneer thicknesses. Results showed that rubber trees are suitable for peeling due to its consistent density ranging from 650 to $706 \mathrm{~kg} / \mathrm{m} 3$. Better visual grades recovery can be obtained when peeling thinner rubberwood veneers. The thickness variation, lathe check depth, length and surface roughness of rubberwood veneers increased with increasing veneer thickness, whereas lathe check frequency decreased with increasing veneer thickness. In general, veneer thickness has more prominent effects on the properties of rubberwood veneer compared to the effect of log radial section.
\end{abstract}

